SUBJECT AREAS: STRUCTURAL PROPERTIES MECHANICAL PROPERTIES CHARACTERIZATION AND ANALYTICAL TECHNIQUES METALS AND ALLOYS

SCIENTIFIC REPORTS: $3: 2113$ DOI: $10.1038 /$ srep02113 (2013)

Published:

3 July 2013

Updated:

5 August 2013

\section{ERRATUM: Visualizing size-dependent deformation mechanism transition in $\mathrm{Sn}$} Lin Tian, Ju Li, Jun Sun, Evan Ma \& Zhi-Wei Shan

Due to a technical error, the Supplementary Movies that accompany this study were not uploaded with the original Article. 